\title{
The wicked problem of chemicals policy: opportunities for innovation
}

\author{
Jennifer H. Allen \\ Published online: 19 April 2013 \\ (C) The Author(s) 2013. This article is published with open access at Springerlink.com
}

\begin{abstract}
Many environmental challenges facing society today, such as climate change and integrated water management, have been described as "wicked problems" due to their biological, physical, and social complexity. Wicked problems extend across media such as air, land, and water; across political jurisdictions and landscape boundaries; and across traditional policy arenas. Traditional policy approaches that are media-specific, rely on single agencies for implementation, and that do not effectively engage stakeholders and partners outside of government are generally ineffective in addressing these issues. The management of toxic chemicals is a classic "wicked problem." Existing toxics policies often exacerbate the "wicked" nature of this issue by ignoring its inherent complexity and the need to bridge across agencies, jurisdictions, and constituencies to effectively manage these substances. Current US policies make it difficult to gather sufficient information to assess the environmental and health impacts of the thousands of chemicals in use. Lack of incentives for industry to invest in safer alternatives has also created a gap between the need for safer chemical alternatives and development of safer technologies, processes, or products. This article explores how policy strategies that foster cross-agency coordination, engage stakeholders in policy development and implementation, and represent a more systems-oriented, holistic approach may be more effective in addressing such complex wicked problems. While federal action is needed to avoid a regulatory "race to the bottom," there are also opportunities for states to encourage the development and adoption of safer alternatives to chemicals of concern.
\end{abstract}

Electronic supplementary material The online version of this article (doi:10.1007/s13412-013-0117-0) contains supplementary material, which is available to authorized users.

J. H. Allen $(\bowtie)$

Institute for Sustainable Solutions, Portland State University,

Box 751 Mail Code SUST, Portland, OR 97207, USA

e-mail: jhallen@pdx.edu
Keywords Wicked problems - Chemicals policy · Policy innovation

This article examines the challenges and opportunities related to the management of toxic chemicals - an issue that can be characterized as a "wicked problem" due to its social, environmental, and economic complexity. It is widely recognized that existing federal regulatory programs have fallen short in addressing the environmental and health impacts of toxic chemicals, despite efforts to develop more comprehensive and preventative approaches. In the absence of federal policy reform, several states have also pursued efforts to encourage a shift toward safer alternatives through toxics reduction efforts and investment in "green chemistry." While federal action is needed to avoid a regulatory "race to the bottom," policy innovations at local and regional levels offer examples of how to encourage the development of safer alternatives to chemicals of concern. Given the continued political and economic challenges to chemical policy reform, strategies that can effectively engage key stakeholders in developing and adopting safer alternatives may hold promise in addressing some aspects of this and other such complex and wicked problems.

\section{Wicked problems}

Many environmental challenges facing society today have been described as "wicked problems" due to their biological, physical, and social complexity. Wicked problems such as climate change, integrated water management, and biodiversity conservation extend across media such as air, land, and water; across political jurisdictions and landscape boundaries: and across traditional policy arenas (Batie 2008; Kreuter et al. 2004). Addressing these challenges often requires behavior change on the part of individuals and organizations (Kreuter et al. 2004). Traditional policy approaches that are media-specific, rely on single agencies for implementation, and that do not effectively engage 
stakeholders and partners outside of government are generally ineffective in addressing these issues (Batie 2008; Kreuter et al. 2004).

Box 1 lists a number of attributes characteristic of "wicked" problems:

Box 1: Attributes of wicked problems (Batie 2008; Australia Public Service Commission (APSC) 2007; Kreuter et al. 2004)

- Difficult to clearly define

- Have many interdependencies and may be "multi-causal"

- Are unstable and continuously evolving

- Have no clear solution

- Involve multiple stakeholders with differing ideas about what the "real" problem is as well as what the causes of problem may be

- Do not fit within responsibility of one organization

- May require changing behavior to resolve

- Characterized by chronic policy failure

That wicked problems face chronic policy failure or shortfall is not particularly surprising when one considers how most policies - particularly regulatory policies - are structured. Regulatory policies tend to be either singularly focused on specific media (air, water, land, etc.) or on individual substances; they also are generally implemented by single agencies, although individual agencies rarely have a mandate comprehensive enough to address the full range of social, environmental, and economic considerations that influence complex issues. Regulations are rarely adaptive; it is unusual for regulatory frameworks to explicitly recognize uncertainty or incompleteness of knowledge and to allow for the incorporation of new information as it becomes available. In addition, regulatory policies often lack mechanisms for the effective engagement of stakeholders and partners outside of government (APSC 2007).

The mismatch between traditional policy approaches and the attributes of wicked problems suggests that alternative or complementary approaches to addressing these issues need to be explored. While the complex and evolving nature of wicked problems means that they rarely can be "solved" (Conklin 2006), there are a number of attributes that may make policies more effective in addressing or at least mitigating the negative impacts of wicked problems. Policies that are more collaborative - especially when there are many stakeholders and power among stakeholders dispersed - tend to be more effective in engaging the range of actors who need to be involved in addressing a particular issue (APSC 2007). ${ }^{1}$ Because wicked issues are by their nature imperfectly understood, policies that are innovative, flexible, and adaptable - that acknowledge the

\footnotetext{
${ }^{1}$ In some cases, however, authoritative strategies combined with collaborative strategies may be useful in addressing a wicked problem, for example, "an expert advisory group" may be best placed to identify the "preferred package of measures after an initial collaborative strategy has been used to identify the full range of views, interconnections, causes and possible solutions" (APSC 2007).
}

incompleteness of current knowledge and the uncertainty inherent in understanding of complex issues - may be better able to evolve as new information becomes available. Understanding and developing solutions to wicked problems requires holistic systems thinking in order to adequately grasp the interrelationships between the multiple causal factors and policy objectives such problems encompass (APSC 2007).

\section{Chemicals management}

The complex nature of toxic chemicals management clearly qualifies this issue as a wicked problem: one that spans both health and environmental policy arenas and that has multiple interconnected economic, social, and environmental facets. Chemical substances "accumulate in the food chain and in human tissue, combine in the environment in unpredictable ways, and flow downstream and downwind, across media and between classes of products" (Allen and Dinno 2011, p. 5). Scientists have linked exposure to toxic chemicals to a wide array of health risks; exposure to even low doses of certain chemicals, particularly in the womb or during early childhood, can result in irreversible and life-long impacts on health (Natural Resources Defense Council (NRDC) 2012). Policies have generally not been structured to take into account the complexity of toxic chemical flows nor do they reflect our uncertainty regarding the direct, synergistic, and/or cumulative impacts of toxic chemicals; instead, they have tended to treat chemicals as if they exist in isolation from their environment, do not combine with each other, and do not flow between media (Allen and Dinno 2011, p. 5).

As a result, current US chemicals policies at all levels fall short in identifying chemicals of concern, managing their risks, and facilitating a shift toward development and use of safer chemicals (US GAO 2007, 2009; Wilson and Schwarzman 2009; Denison 2007; Lowell Center for Sustainable Production 2008; Rosenbaum 2010). The current federal policy framework has resulted in three major gaps related to data, safety, and technology (Wilson and Schwarzman 2009):

Data gap: Manufacturers and businesses can sell a chemical or product without providing sufficient information about its potential health or environmental hazards to enable agencies or consumers to adequately assess the environmental and health impacts of these chemicals (US GAO 1994; Wilson and Schwarzman 2009; Allen and Dinno 2011). There is little incentive for companies to develop better information because doing so voluntarily may increase the likelihood that they will uncover evidence of harm, thus triggering government action (Denison 2007; Allen and Dinno 2011).

Safety gap: The current policy framework makes it difficult to gather the information needed to evaluate 
potential human health and environmental impacts of chemicals; current policies require government agencies to prove beyond a reasonable doubt that chemicals pose a certain level of risk without giving these agencies access to adequate data to prove such risk (Wilson and Schwarzman 2009; Allen and Dinno 2011). As a result, little is known about which chemicals may pose risks, what the magnitude of these risks may be, or which chemicals pose slight or no risk and might serve as safer substitutes (Denison 2007). The lack of information contributes to continued and widespread human exposure to harmful chemicals, as documented by the Centers for Disease Control and Prevention (2009).

Technology gap: There is a "disconnect" between the need for safer chemical alternatives and investment in alternatives assessment and development of safer technologies, processes, or products (Wilson and Schwarzman 2009; Allen and Dinno 2011). Industry has little incentive to prioritize development of safer alternatives in the absence of information about the risks posed by particular substances to the environment or human health; the lack of information about chemicals' impacts on health and the environment also distorts the market for chemicals by preventing product safety from being taken into account in purchasing decisions, leaving these social costs out of the equation (Wilson et al. 2008; Allen and Dinno 2011).

These gaps result in large part from the way that toxics management is structured at the federal level, and in particular, the way that the Toxic Substances Control Act was designed. The federal government has the primary responsibility for managing chemicals in the USA and the Toxic Substances Control Act (TSCA) is the primary federal law regulating chemicals in the USA. ${ }^{2}$ Under TSCA, the Environmental Protection Agency (EPA)'s Office of Pollution Prevention and

\footnotetext{
${ }^{2}$ Several federal agencies share responsibility for regulation of chemicals, including the Environmental Protection Agency (EPA), the Food and Drug Administration (FDA), and the Consumer Product Safety Commission (CPSC). The EPA regulates the testing and manufacture of chemical substances and is responsible for managing the risks related to chemical use and disposal. The FDA regulates chemical substances in food, cosmetics, and "food contact materials" such as packaging, while the CPSC is responsible for overseeing chemical exposures related to consumer products. The National Toxicology Program's Office of Health Assessment and Translation conducts evaluations to assess the evidence that environmental chemicals, physical substances, or mixtures cause adverse health effects and provides opinions on whether these substances may be of concern given what is known about current human exposure levels. These agencies are guided by different statutes: the Federal Hazardous Substances Act and the Consumer Product Safety Act regulate chemicals in consumer products, including labeling requirements for hazardous materials and restrictions of some chemicals. The Federal Food Drug and Cosmetic Act regulates cosmetic products; pesticides are regulated by the Federal Insecticide, Fungicide, and Rodenticide Act; and the Food, Drug, and Cosmetic Act regulates pharmaceuticals and food additives.
}

Toxics is responsible for assuring that chemicals that are manufactured, imported, processed, or distributed in commerce or that are used or disposed of in the USA do not pose any "unreasonable risks" to human health or the environment. $^{3}$

EPA has the authority to ban the manufacture or distribution of chemicals that pose unreasonable risks to human health or the environment; EPA can also limit use of these chemicals, require labeling, or impose other restrictions. However, EPA can only take such actions after determining that a chemical substance "presents or will present an unreasonable risk of injury to health or the environment." The term "unreasonable risk" is a risk-benefit standard, meaning that EPA must consider risks, costs, and benefits of a substance to be regulated, including the availability of substitutes, in determining whether and how to restrict chemical use. TSCA requires the EPA administrator to impose the "least burdensome" regulatory measure that will provide adequate protections.

EPA can also require that manufacturers test chemicals, but because of the burden of proof EPA must show, it has exercised this authority on only approximately 200 of the more than 84,000 chemical substances listed in the TSCA Chemical Substance Inventory as being produced, processed, or imported for commercial purposes in the USA (Owens 2010). In order to exercise this authority, EPA must make certain statutory findings about the substance involved; such findings include a lack of sufficient data to determine the effects of the substance on health and/or the environment, the necessity of testing to provide such data, the unreasonable risk of injury that a substance might pose to health or the environment, and other related considerations (GAO 2009).

The structure of TSCA contributes directly to the data, safety, and technology gaps described above by restricting EPA's ability to gather information about chemicals without prior evidence that they pose harm and by creating disincentives for industry to provide data about chemicals voluntarily or to pursue the development of safer alternatives. While intended to prevent chemicals of concern from entering the marketplace, the burden of proof on the EPA, combined with the enormous number of chemicals already in use when TSCA went into effect, has limited EPA's ability to effectively assess the impacts of chemicals on human health and the environment. TSCA provided no mechanism for policy adaptation as the challenges of chemical assessment became more evident, and it provides no avenue to incorporate incentives that could direct industry toward investment in

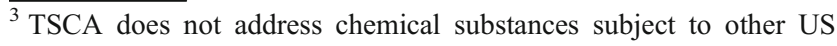
statutes, such as those noted in the previous footnote as well as tobacco, nuclear material, or munitions.
} 
alternatives that would be safer. When one revisits the attributes of policies that can best address complex, evolving, wicked problems like toxics management-adaptability, recognition of uncertainty, and engagement of stakeholders in a collaborative process-TSCA clearly falls well short.

\section{Upstream efforts and reform}

The shortcomings of TSCA are well recognized, and there have been a number of efforts to address these weaknesses and adopt more collaborative and upstream approaches to address toxics management as well as other environmental concerns. In the 1980s, "pollution prevention" strategies emerged with a focus on preventing problems before they arose; the Pollution Prevention Act of 1990 focused on "source reduction" practices to reduce the amount of hazardous substances being released into the environment. The pollution prevention movement and the regulatory reinvention effort of the 1990s included a number of initiatives that sought to engage stakeholders in policy development and implementation; both the "eXcellence in Leadership" or "XL" project and the Common Sense Initiative involved significant engagement with stakeholders, seeking consensus around sector-based approaches to pollution prevention and moving away from the " pollutant-by-pollutant, media-by-media approach to regulation" (Environmental Protection Agency 1998). The Aspen Institute, Keystone Institute, and many localities also employed multistakeholder engagement approaches for environmental problem solving during this timeframe, and EPA has increasingly recognized that a "broader program of integrated voluntary and regulatory actions, with greater emphasis on stakeholder involvement" would be necessary to "elevate environmental stewardship to the next level that the nation requires" (Battelle 2003, p. 3).

Reform of TSCA itself has been under debate in Congress over the past several years, although no legislative reforms have been passed. The proposed "Kid Safe Chemical Act" and the "Toxic Chemicals Safety Act of 2010" would each have placed responsibility on chemical companies to prove their products safe before putting them on the market, a shift in accountability from the existing structure which allows usage until and unless the government can demonstrate a level of hazard that requires action. The bills would also have required businesses to reveal which chemicals they use and to show that there is a "reasonable certainty that no harm will result" from all intended uses over the life cycle of a chemical. EPA would have been required to consider aggregate exposure to chemicals from many sources when making a safety determination, and to take into account vulnerable populations, such as children or those with immune disorders, in setting exposure limits or other restrictions. As such, these acts would have addressed a number of data and safety considerations.

Several recent federal initiatives attempt to fill key data gaps and to develop a more comprehensive information system that would consolidate the information regarding chemical uses and their impacts, which is currently dispersed and fragmented. The voluntary High Production Volume Chemical Challenge focuses on developing basic screening information on the potential hazards of approximately 2,000 of the highest volume chemicals in use in the USA, although such screening level data may not be sufficient to adequately inform safety-related decisions (Denison 2007). There has been increasing recognition as well of the need for more investment to advance the development of alternative products, technologies, and processes to offer safer alternatives to existing chemical substances. The Green Chemistry Research and Development Acts of 2005 and 2007 established a Green Chemistry Research and Development Program to promote and coordinate federal research, development, demonstration, education, and technology transfer activities related to green chemistry and authorized appropriations to invest in research and development related to green chemistry for the National Science Foundation, National Institute of Standards and Technology, Department of Energy, and EPA. The Federal Economy, Energy, and Environment program is a coordinated federal and local technical assistance initiative to help manufacturers shift their processes toward more sustainable practices; the assessments and training target opportunities to maximize energy efficiency, reduce environmental wastes, identify opportunities for reducing carbon emissions, promote sustainable manufacturing practices and growth, and reduce business costs (Environmental Protection Agency 2012).

\section{A role for the states in policy innovation}

Given that chemicals and the products that contain them flow across state and national boundaries, a strong federal framework for chemicals policy is essential in order to provide a level playing field for businesses to prevent them from locating in states that have lower policy standards, and to address the fact that trade in chemicals and in the products they are used in crosses state and international boundaries. While acknowledging the essential role of national efforts, however, state-level policies offer an opportunity to experiment in ways to address some of these policy gaps. As Supreme Court 
Justice Louis Brandeis stated, "a single courageous state may, if its citizens choose, serve as a laboratory and try novel social and economic experiments without risk to the rest of the country" (US Supreme Court 1932, p. 311). States can serve as laboratories for other states as well as for the federal government (Boeckelman 1992). Approaches that are more regionally or locally "place-based" may also be more effective in addressing social, economic, and environmental issues in a more integrated manner and in mobilizing buy-in from key stakeholders (Prugh et al. 2000; Gardner et al. 2011). Given "the ongoing deadlock in Congressional efforts to amend TSCA to address its deficiencies, the role of state laws merits attention" (Nash 2012, p. 3).

Recognizing the shortcomings of regulatory action on chemicals policy at the federal level, a number of states have taken action to address gaps in chemicals management. State-level initiatives of particular note include Massachusetts' Toxic Use Reduction Act (TURA), California's Green Chemistry Initiative and recently proposed Safer Consumer Products Regulation, Washington's "Reducing Toxic Threats" initiative and Children's Safe Product Act of 2008, and Oregon's Toxic Reduction Strategy and Green Chemistry Innovation Initiative. ${ }^{4}$

Massachusetts's TURA, enacted in 1989 and amended most recently in 2006, requires companies that use large quantities of specific toxic chemicals to make a "good faith" effort to evaluate pollution prevention opportunities with respect to their current chemical usage. Although TURA does not require that companies take action as a result of these evaluations, this program has reduced toxic chemical use by $40 \%$, toxic by-products by $71 \%$, and toxic releases to the environment by $91 \%$ (Massachusetts Department of Environmental Protection 2013). The Office of Technical Assistance in the Executive Office of Environmental Affairs provides free technical consultation and assistance to firms attempting to implement a Toxics Use Reduction program, while the Toxics Use Reduction Institute at the University of Massachusetts Lowell provides education and training in toxics use reduction for professionals and the general public, conducts a technology transfer program, and sponsors research in the development of safer materials and cleaner technologies.

California's Green Chemistry Initiative includes a focus on identifying and prioritizing chemicals of concern in consumer products and evaluating safer alternatives to toxic

\footnotetext{
${ }^{4}$ For more information on these initiatives, see the following websites: http://www.mass.gov/dep/toxics/toxicsus.htm (Massachusetts), http:// www.dtsc.ca.gov/PollutionPrevention/GreenChemistryInitiative/ index.cfm (California), http://www.ecy.wa.gov/programs/swfa/rules/ ruleChildren.html (Washington), and http://www.deq.state.or.us/toxics and http://www.oregon.gov/gov/docs/executive_orders/eo_12-05.pdf (Oregon)
}

chemicals; a Green Ribbon Science Panel and an online Toxics Information Clearinghouse have also been established. California's proposed Safer Consumer Products regulation, introduced in July 2012, would use a recognized list of "chemicals of concern" to guide a process requiring manufacturers using any of the listed chemicals to identify and examine the viability of using safer alternatives. The proposed regulation was developed with input from a wide group of stakeholders including the Green Ribbon Science Panel, business groups, and representatives of the health care and environmental communities.

Washington's Reducing Toxic Threats Initiative focuses on preventing exposures to toxics, with the Children's Safe Product Act (CSPA) as an important part of the initiative. The first part of the CSPA, which limited the amount of lead, cadmum, and phthalates allowed in children's products sold in Washington, was preempted by the 2008 US Consumer Products Safety Improvement Act pass in July 2008. The second part of the CSPA requires the Department of Ecology to consult with the WA Department of Health to develop a list of chemicals that manufacturers must report on-these chemicals are known to be toxic and have either been found in children's products or have been documented to be present in human tissue.

Oregon has taken a number of actions recently to address chemicals management. In December 2011, the Oregon Department of Environmental Quality issued a draft Toxics Reduction Strategy (DEQ 2012), and in April 2012, Oregon Governor Kitzhaber issued Executive Order 12-05, "Fostering Environmentally Friendly Purchasing and Product Design" (State of Oregon, Office of the Governor 2012-see Appendix 2). DEQ's Draft Toxics Reduction Strategy takes an integrated approach to reducing toxic chemicals and pollutants, moving away from the previous "media-specific" strategies (Oregon Department of Environmental Quality (DEQ) 2012). The strategy focuses on the highest priority toxic chemicals and seeks to reduce toxics at their source whenever feasible. The draft strategy explicitly promotes a partnership approach, seeking to engage with other agencies and organizations to increase the effective use of public and private resources through greater alignment and coordination (DEQ 2012). This partnership commitment, by recognizing that managing chemicals required broad engagement of multiple organizations, helps to mitigate the fragmentation of responsibilities across agencies. The strategy also proposes using environmental outcome statistics to measure the effectiveness of strategy implementation; by including this requirement, the policy shifts from the single chemical focus toward a strategy that allows for adaptation based on what actions appear to be most effective in addressing impacts on the ground-a more useful 
approach than trying to chase multiple chemicals through the system.

Governor Kitzhaber's Executive Order established the "Oregon Green Chemistry Innovation Initiative" to focus on building awareness among businesses of the competitive opportunities that adopting or developing alternatives to chemicals of concern may offer and provides mechanisms to help businesses identify the specific opportunities relevant to their enterprise (State of Oregon, Office of the Governor 2012). The Order directs state agencies to work with universities and other partners to provide funding and incentives to foster innovation and support businesses in pursuing safer alternatives. The initiative seeks to strengthen demand for safer alternatives by incorporating environmentally preferable purchasing into public sector procurement policies, harnessing the market to provide additional incentives for the development of safer alternatives. The Executive Order also directs DEQ to determine if there are ways to "more effectively promote and support green chemistry in Oregon businesses and institutions," and to identify at least two industries where green chemistry should be applied to reduce the use and generation of chemicals of concern included in the Toxic Reduction Strategy Focus list. DEQ is directed to develop voluntary action plans for these industries "that emphasize opportunities to use green chemistry in ways that protect human health and the environment" (State of Oregon, Office of the Governor, p. 5). ${ }^{5}$

The actions taken by California, Washington, Massachusetts, and Oregon incorporate a number of the attributes recommended to address complex issues such as chemicals policy. The approaches emphasize collaboration, fostering innovative in the private sector, and take an outcomeoriented approach that provides for flexibility as new information becomes available. Most of these efforts have successfully engaged a broad set of actors both within and outside of government and support efforts that provide information to businesses and the public that can lay the foundation for more informed decision making and behavior change. The focus on the opportunities related to green chemistry may help address the uncertainty regarding the potential effects of the many existing chemicals in use, and integrating economic considerations and market opportunities into the strategies harnesses the self-interest of the business community.

In addition to the actions that have been taken to date by these states, there may be opportunities to expand interdisciplinary education and workforce development programs to foster the skills in systems thinking and collaborative

\footnotetext{
$\overline{5}$ These actions reflect several of the suggestions made in the 2011 publication, "Leadership in Chemicals Policy: Opportunities for Oregon" (Allen and Dinno 2011). Appendix 1 describes in greater detail the recommended actions in each of these areas.
}

management needed to address complex problems (Allen and Dinno 2011). By investing in such programs, the states can help lay a foundation for ongoing innovation and problem solving related to the challenges of chemicals management and other wicked problems. The Interstate Chemicals Clearinghouse that has been launched to help local, state, and regional governments, businesses and nongovernmental organizations advance their efforts toward safer chemicals and products will also help advance these efforts (Geiser and Goldberg 2010).

\section{The gaps remain}

Despite the efforts to develop more upstream, preventative, and collaborative policy approaches at federal and state levels, the data, safety, and technology gaps continue to constrain effective management of toxics and limit the incentives for industry to explore the development of safer alternatives. The lack of progress in addressing these gaps can be attributed to a number of factors, including political opposition, inadequate investment of resources for testing, enforcement, and development of safer alternatives, and the inherent complexity of chemical flows, interactions, and impacts.

Political opposition to policy reform has been an ongoing challenge; because chemicals play a central role in key economic sectors, business and industry are wary that regulatory reform and more precautionary approaches will harm their profitability and competitiveness. The economic value that chemicals represent in the industrial and commercial sector contributes to the challenges of developing more comprehensive policy frameworks. US chemical producers contribute $2.1 \%$ of the total US GDP and $12 \%$ of the total value of US manufacturing output (Istockanalyst 2011); the US chemical industry is the country's largest exporter with exports valued over $\$ 171$ billion and an overall value of $\$ 720$ billion (American Chemistry Council 2011). Underdevelopment of safer alternatives to toxic chemicals contributes to the concern in some business sectors about potential negative economic impacts of policies that might further restrict chemicals currently available for use. Given these concerns, it is not surprising that a high percentage of EPA's proposed actions to revise chemicals policy are contested in court, as well as being delayed or weakened based on costbenefit and small business impact assessment requirements (Cooper 2010).

The chronic underfunding of the agencies charged with enforcing existing policies has also limited the effectiveness of these programs. However, even with a vast increase in resources for assessment and enforcement, it is not clear that a purely regulatory policy approach would be successful in evaluating the safety of so many chemicals, given the 
innumerable ways that chemicals can combine with each other and the variable susceptibility to harm among different populations and individuals. Even efforts that seek to promote more proactive approaches face funding constraints; in April 2012, EPA canceled the \$20 million solicitations for two green chemistry-related efforts: the Centers for Material Life Cycle Safety and the Centers for Sustainable Molecular Design. While EPA continues to support efforts in the green chemistry area, reducing such investments threatens efforts to develop safer alternatives to chemicals of concern.

\section{Reflections and concluding comments}

Chemicals management clearly qualifies as a wicked problem-it is difficult to clearly define the boundaries of the issue, as it is characterized by many interdependencies and has multiple causes. The situation with respect to chemicals of concern is unstable due to the continued introduction of new chemicals and the lagging understanding of the impacts of chemicals already in use. There is no clear solution to addressing the known or potential impacts of the 84,000 chemicals in use, and there are multiple stakeholders involved with different perspectives on what the "real" problem is, what the causes of this problem are, and how it could be addressed. Although EPA has authority over regulation of chemicals under TSCA, EPA alone cannot address this challenge; mitigating the impacts of the chemicals already in use will require that multiple actors change their behavior to avoid exposure and create more demand for safer alternatives. Given the poor fit between the complexity of the issue and the policy framework in place to address it, it is understandable that chemicals management has been characterized by chronic policy failure at the federal level.

Because no one actor can address the challenges related to chemicals management, to be effective policies must engage citizens, industry representatives, nonprofits, universities, and government agencies to develop a shared framework of action. The process of policy development and implementation must be an adaptive one that allows for new knowledge to enter and inform strategies over time. Finding ways to harness economic opportunities related to a shift toward safer alternatives can help mitigate the concerns of industry and achieve more sustainable solutions. Clearly, the current federal policy framework does not reflect these principles. While there have been efforts to reform TSCA to address these shortcomings, federal reforms remain stalled and the possibility of creating a policy framework at the national level that reflects these characteristics is daunting, particularly given concerns over possible economic impacts on industry of any changes in the regulatory structure (Allen and Dinno 2011).

The approaches being taken in California, Massachusetts, Oregon, and Washington recognize that no one actor can solve this or any other wicked problem alone and therefore promote strategies that proactively engage a broad group of actors. They also recognize that no single strategy or approach can address all of the shortcomings of current chemicals policy; a combination of regulatory and voluntary efforts will be needed to create an environment that fosters ongoing innovation in the development of effective alternatives to chemicals of concern. These approaches explicitly recognize the complexity and ongoing uncertainty of chemicals management and focus on flexible, collaborative solutions rather than relying on more rigid, "one size fits all" regulatory options as the only possible approach. Furthermore, by recognizing the inter-related economic, environmental, and social factors that shape this issue and seeking solutions that can provide positive outcomes on all of these fronts, these policies create a stronger foundation for engagement among public and private stakeholders.

While the actions taken by these and other states offer some innovative frameworks, it is important to recognize that states in general have very limited resources, are constrained in addressing trans-boundary problems, and can face significant obstacles to effectively challenging economic interests that may be threatened by policy reform efforts. In addition, while state-level innovation may offer some examples that can be replicated elsewhere, the development of a "patchwork quilt" of different regulations across different states runs the risk of fostering a "race to the bottom" where businesses seek locations with minimal regulatory requirements.

While action at national and international levels will be important to address chemicals management however, action at state and local levels may inform and catalyze efforts at other scales. By offering an arena where experiments in policy and partnership can be undertaken and alternative approaches explored, state-level action can create a platform for shared learning and policy innovation.

Chemicals management is just one example of a wicked problem facing society. The approaches described above may be relevant to other complex challenges, just as climate change, integrated management of water resources, the obesity epidemic, and even some of the systemic economic challenges facing society today such as funding for education and health care. Approaches that bridge government agencies, engage partners outside of government in collaborative efforts, and that seek to foster different ways of 
"doing business" among groups and individuals can harness the respective strengths of public and private sector organizations and align resources toward more systemic solutions.

Open Access This article is distributed under the terms of the Creative Commons Attribution License which permits any use, distribution, and reproduction in any medium, provided the original author(s) and the source are credited.

\section{References}

Allen JH, Dinno A (2011) Leadership in chemicals policy: opportunities for Oregon. Portland State University. http://www.pdx.edu/sites/ www.pdx.edu.sustainability/files/media assets/Chemical Leadership.pdf. Accessed 1 Nov 2012

American Chemistry Council (2011) Chemical industry facts and figures. http://www.americanchemistry.com/chemistry-industryfacts. Accessed 14 July 2012

Australian Government: Australian Public Service Commission (APSC) (2007) Tackling wicked problems: a public policy perspective. Australian Public Service Commission, Canberra, Australian Government

Batie SS (2008) Wicked problems and applied economics. Am J Agric Econ 90(5):1176-1191

Battelle (2003) Overview: Office of Pollution Prevention and Toxics Programs. Prepared for U.S. Environmental Protection Agency Office of Pollution Prevention and Toxics

Boeckelman K (1992) The influence of states on federal policy adoptions. Pol Stud J 2(3):365-375

Centers for Disease Control and Prevention (2009) Fourth national report on human exposure to environmental chemicals. Department of Health and Human Services, Atlanta

Conklin J (2006) Dialog mapping: building shared understanding of wicked problems. Wiley, Chichester

Cooper PJ (2010) The war against regulation: from Jimmy Carter to George W. Bush. University Press of Kansas, Lawrence

Denison RA (2007) Not that innocent: a comparative analysis of Canadian, European Union and United States policy on industrial chemicals. Environmental Defense in Cooperation with Pollution Probe, Washington, DC

Environmental Protection Agency (2012) http://www.epa.gov/ greensuppliers/e3.html. Accessed 12 Nov 2012

Environmental Protection Agency (1998) Common sense initiative: lessons learned about protecting the environment in a common sense, cost effective ways. Environmental Protection Agency, Washington, DC

GAO (2009) Testimony before the Subcommittee on Commerce, Trade, and Consumer Protection, Committee on Energy and Commerce, House of Representatives. CHEMICAL REGULATION. Options for Enhancing the Effectiveness of the Toxic Substances Control Act: Statement of John Stephenson, Director Natural Resources and the Environment

Gardner B et al (2011) Comprehensive community initiatives: promising directions for "wicked" problems? HORIZONS. Policy Research Initiative
Geiser K, Goldberg T (2010) Envisioning the future of the interstate chemicals clearinghouse. http://www.newmoa.org/prevention/ webconferences/plancom/IC2_Future.pdf. Accessed 22 May 2011

Istockanalyst (2011) Chemical industry - a keystone of the US economy March 21, 2011. Istockanalyst.com. Accessed 11 July 2012

Kreuter MW, De Rosa C, Howze EH, Baldwin GT (2004) Understanding wicked problems: a key to advancing environmental health promotion. Health Ed Behav 31(4):441-454

Lowell Center for Sustainable Production (2008) Options for state chemical policy reform: a resource guide. University of Massachusetts Lowell, Lowell

Massachusetts Department of Environmental Protection (2013) Toxics and hazards. http://www.mass.gov/dep/toxics/tura/awards.htm. Accessed 5 March 2013

Nash J (2012) The Massachusetts Toxics Use Reduction Act: a model for nanomaterials regulation? Harvard Kennedy School Mossavar-Rahmani Center for Business and Govenrment. MRCBG Associate Working Paper Series No. 9

Natural Resources Defense Council (NRDC) (2012) Take out toxics: more than 80,000 chemicals permitted in the United States have never been fully assessed for toxic impacts on human health and the environment. http://www.nrdc.org/health/toxics.asp. Accessed 11 July 2012

Office of the Governor, State of Oregon (2012) Executive Order 12-05. Oregon Green Chemistry Innovation Initiative

Oregon Department of Environmental Quality (Oregon DEQ) (2012) Draft Toxics Reduction Strategy. http://www.deq.state.or.us/ toxics/\#Reduction. Accessed 11 July 2012

Owens S (2010) Testimony of Steve Owens, Assistant Administrator Office of Prevention, Pesticides and Toxic Substances, U.S. Environmental Protection Agency before the Subcommittee on Superfund, Toxics, and Environmental Health Committee on Environment and Public Works United States Senate, February 4, 2010. http://www.epa.gov/ocspp/pdfs/steveowens.feb042010.pdf. Accessed 23 May 2011

Prugh T, Costanza R, Daly H (2000) The local politics of global sustainability. Island, Washington, DC

Rosenbaum W (2010) Environmental politics and policy. CQ, Washington, DC

US Supreme Court (1932) New State Ice Co. v. Liebmann, 285 U.S. 262, 311 (dissent)

U.S. General Accounting Office (U.S. GAO) (1994) Toxic Substances Control Act: legislative changes could make the act more effective. (GAO/RCED-94-103). http://archive.gao.gov/t2pbat2/ 152799.pdf. Accessed 23 May 2011

U.S. General Accounting Office (U.S. GAO) (2007) Chemical regulation: comparison of U.S. and recently enacted European Union approaches to protect against the risks of toxic chemicals. http:// www.gao.gov/new.items/d07825.pdf. Accessed 23 May 2011

U.S. General Accounting Office (U.S. GAO) (2009) Chemical regulation: observations on improving the Toxic Substances Control Act. Testimony before the Committee on Environment and Public Works, U.S. Senate. http://www.gao.gov/htext/ d10292t.html. Accessed 23 May 2011

Wilson MP, Schwarzman MR (2009) Toward a new U.S. chemicals policy: rebuilding the foundation to advance new science, green chemistry and environmental health. Environ Heal Perspect 117:1202-08

Wilson MP, Schwarzman MR, Malloy TF, Fanning EW, Sinsheimer PJ (2008) Green chemistry: cornerstone to a sustainable California. The Centers for Occupational and Environmental Health, University of California, Berkeley 